\title{
El Taller de Diseño Integrado (1968-1973): una experiencia de trabajo colaborativo en la escena artística chilena ${ }^{1}$
}

\section{The Integrated Design Workshop (1968-1973): a collaborative work experience in the Chilean art scene}

\author{
Stella Salinero Rates \\ Universidad de Chile \\ stellasalinero@gmail.com
}

\author{
Mónica Salinero Rates \\ Universidad de Chile \\ monicasalinero@gmail.com
}

\section{Resumen}

El Taller de Diseño Integrado (DI) fue un colectivo artístico que trabajó entre los años 1968 y 1973. Su formación multidisciplinar les permitió adquirir una mirada más amplia sobre los fenómenos a los que se avocaron, entre ellos, el diseño y la implementación del emblemático "Paso Bajo Nivel de Santa Lucía" en Santiago. La práctica del DI implicó una nueva mirada conceptual y material sobre el arte y el diseño, en la que se priorizó la experimentación y lo multidisciplinar y el trabajo colaborativo sobre el individual. A través del análisis de sus conceptos claves, "diseño-integrado" y "taller", se propone revisar y comprender sus principales ideas y propuestas, ejemplificadas en prácticas y obras concretas.

Palabras Clave: colectivo artístico, arte y espacio público, diseño integrado a la arquitectura.

\section{Abstract}

The Taller de Diseño Integrado (DI) was an art group that worked between 1968 and 1973. Their multidisciplinary training helped them to improve their view of art and its role in society. We owe them the design and implementation of Santiago's emblematic urban art work "The Santa Lucía underpass". The DI practice involved new ideas about art material and the multidisciplinary point that they held over art and desing. They prioritized collaborative art practice over individual art practice. Through analizing their key ideas of "integrated design" and "workshop", we will review and try to understand their main ideas and proposals, from their own work and practices.

Keywords: Artistic Collective, Art and Public Space, Design Integrated in Architecture.

1 Este trabajo ha sido fruto del proyecto de investigación "Imágenes de una ciudad Moderna: Santiago y el Taller de Diseño integrado" financiado por el Fondo de Fomento para las Artes, FONDART 2012. 


\section{Introducción}

El DI se formó en 1968 por iniciativa del artista visual y académico de la Universidad de Chile Carlos Ortúzar, quién le propuso al también artista y académico, Eduardo Martínez Bonati, trabajar juntos en la realización de proyectos para el espacio público, combinando el arte, el diseño y la arquitectura. Martínez Bonati ya venía trabajando en esta línea en obras como los murales de hormigón del Instituto Nacional de Capacitación (INACAP) de Concepción (1968-1970)² o en el mural del auditorio de la Facultad de Agronomía de la Universidad de Chile en el campus Antumapu3. Al poco tiempo se suma Iván Vial y ganan el concurso para la realización de las obras del Paso Bajo Nivel Santa Lucía (1970). Posteriormente ingresa al DI la artista visual y académica de la Universidad de Chile, Angélica Quintana.

Uno de los rasgos distintivos del DI fue la riqueza de la formación multidisciplinar de sus miembros, la cual los dotó de una gran plasticidad y versatilidad, la que se refleja en el carácter sincrético y mixto de sus obras. Esta plasticidad les permitió situarse en medio de las disciplinas e ir nutriéndose de una serie de fuentes que posibilitaron generar un conocimiento mayormente aprehensible en la práctica, es decir, produjeron un conocimiento desde el hacer, desde su particular metodología consistente en enfrentarse a sus obras como un taller colectivo. Una breve mirada a las áreas de desempeño de los integrantes del DI da cuenta de la multidisciplinariedad que señalamos. Eduardo Martínez Bonati ${ }^{4}$ es pintor, grabador y muralista en hormigón; Carlos Ortúzar cursó estudios de filosofía y realizó la licenciatura en artes en la Universidad de Chile, posteriormente hizo una especialización en materiales en el Center for Advanced Visual Studies del MIT (1970), aunque también se dedicó paralelamente al diseño de objetos para la tienda de diseño y muebles TERRA; Vial estudió construcción civil, fue pintor, bailarín, diseñador de vestuario y escenografías para el ballet de Teatro Municipal, así como director y conductor del primer programa de televisión sobre Arte en Chile titulado Forma y espacio (1968) ${ }^{5}$. Esta diversidad en las experiencias formativas de los integrantes del DI es de suma relevancia para comprender el pensamiento y la práctica posterior del grupo, los

2 Paradigmática obra del modernismo chileno que fue derribada el año 2008, realizada por Miguel Lawner durante el gobierno de Eduardo Frei Montalva. Respecto al edificio comenta Miguel Lawner: "este edificito que está como en el corazón del conjunto, todo su zócalo quedó decorado con murales de hormigón que hizo Bonati y también la caja de la escalera que es todo de hormigón el interior. (Entrevista personal a Miguel Lawner 2012). Esta fue la primera obra en la que Martínez Bonati trabajó con hormigón para decorar muros exteriores.

3 Este mural de hormigón lo realizó Eduardo Martínez Bonati junto a sus alumnos del Taller de Grabado de la Universidad de Chile, cuyo tema fue el proceso de polinización y nos cuenta que su diseño es "una flor diseccionada que se va hacia la abstracción" (Entrevista 2012).

4 Además fue miembro del destacado grupo SIGNO (1961-1963) junto a José Balmes, Gracia Barrios y Alberto Pérez, que rompe la representación tradicional de la pintura (caballete) cultivando un informalismo de corte social y político.

5 En este programa Iván Vial realizaba entrevistas a otros artistas, mostrando el panorama artístico que se vivía en el país, "en el cual se debatieron algunos de los aspectos relativos a nociones del arte en su modernidad y contemporaneidad, tópicos inéditos para algunos sectores de la creación local de este tiempo" (Navarrete 24). 
cuales expresan la convergencia de una multiplicidad de influencias por parte de los importantes movimientos artísticos de la época, en los cuales se vieron imbuidos en sus estudios y prácticas artísticas durante su estadía en el Pratt Institute de Nueva York durante la década de los 60. El DI proyectó una serie de obras integradas a la arquitectura tanto en la ciudad de Santiago como en otras ciudades del país; algunas de las cuales aún existen, otras lamentablemente han desaparecido, han sido destruidas o fueron proyectadas como obras efímeras. Podemos mencionar las siguientes obras ejecutadas y proyectadas por el grupo: escultura cinética encargada por la empresa Peugeot ${ }^{6}(1969)$, el Paso Bajo Nivel de Santa Lucía (1970), shows luminotécnicos (1970), diversos murales en instituciones públicas (Hospital de trabajador, Aeropuerto de Antofagasta, Carabineros, UNTAC III), la obra interactiva El cubo (1971), un proyecto para la realización de un área común en la remodelación San Borja. Pese a su abundante producción como colectivo, hasta la fecha no existen publicaciones en torno al DI, salvo referencias puntuales en alguna obra mayor (Galaz e Ivelic 1988 o Navarrete 2010).

A grandes rasgos su idea en torno al diseño integrado a la arquitectura estaba guiada por lo que llamó Eduardo Martínez Bonati "el contexto del medio ambiente urbano" por la necesidad de socializar y expandir el campo de acción del arte (que se encontraba atomizado en los museos y galerías), utilizando las formas de producción industrial y desde allí instalarse en la vida moderna. Es decir, aplicar los conocimientos sobre materiales, diseño y arquitectura al espacio público urbano y en el diseño de objetos y producción de arte. Entonces, se constituyen dos grandes líneas en el trabajo del DI, la de impacto en el paisaje urbano y la de inserción a nivel de consumo de arte. Martínez Bonati expresa los objetivos del DI que señalan esos dos rangos:

La teoría mía era que si lo hacíamos bien, tú podías ir al supermercado y había una sección donde había objetos de arte a precio muy económico, porque se utilizaba la industria para producir, al precio de un libro, de un disco como mucho. Cuándo veas que nos meten al carrito es porque hemos ganado. Siempre fui de la idea que el arte no podía ser exclusivo a las galerías y los museos, había que sacarlo de allí, sacarlo y con estas dos posiciones era posible hacerlo: incorporarlo al contexto del medio ambiente urbano y lo otro, la incorporación de nuevas tecnologías industriales. (Entrevista personal 2012)

6 Debemos hacer notar que durante esta época muchas empresas tanto públicas como privadas, comenzaron a encargar obras a artistas para instalarlas en sus edificios corporativos, como lo fue la escultura mural para las aerolíneas Varic (1968) o el mural cinético para el Banco de Concepción (1969), ambas obras realizadas por Carlos Ortúzar, o el trabajo de hormigón en los muros exteriores de la empresa CIC que hizo Federico Assler (1961), los muros del INACAP de Concepción realizados por Eduardo Martínez Bonati, por nombrar algunos ejemplos. 


\section{Arte y diseño integrado al medio ambiente urbano}

La práctica del DI estuvo orientada por la voluntad de desarrollar obras contextualizadas diseñadas para un espacio y/o entorno particular, lo que Martínez Bonati denominó "el contexto del medio ambiente urbano" (Entrevista personal 2012). En un movimiento de expansión de los límites de arte, los y las artistas comenzaron un tránsito hacia el espacio público, a la vez que surgía fuertemente la idea de integrar arte y diseño al entorno urbano ${ }^{7}$.

Estas ideas confluyeron gracias a la posibilidad de la producción de obra en base a material industrial (cerámica, hierro, aluminio, vitrocerámica, acrílico, fibra de vidrio, hormigón) que permitía salir al espacio público, a la intemperie, con menores costos y mayor resistencia que otros materiales. Los materiales industriales permitían nuevas formas y experiencias sensoriales y abrirse a un "público" masivo y espontáneo, salir al encuentro del espectador representado por el sujeto de la ciudad moderna, ya fuese en sus variantes de peatón o automovilista. Es en este sentido que el concepto de diseño integrado denominaba un campo de acción en el espacio público y entorno urbano, que implicaba la proyección de obras en conjunto con el diseño urbano y arquitectónico ${ }^{8}$. Lo que nos resulta especialmente importante del concepto diseño integrado es que se inserta en el proceso de proyección de la obra urbana y no sólo como un aderezo. Junto con ello, lo integrado connota todo aquello que está presente en nuestra vida cotidiana y que es experimentado a través de los sentidos, no exclusivamente desde una actitud contemplativa, sino también a través de la experiencia táctil.

El DI realizó trabajos en esta línea a través de la adjudicación de dos concursos que realizara la Corporación de Mejoramiento Urbano (CORMU) ${ }^{9}$ y la participación de los tres artistas con obras integradas al edificio de la UCTAD III (actual GAM) y en especial la acción de Martínez Bonati en la comisión del edificio. El artista organizó y gestionó la integración de 36 obras, desde murales, bebedores de agua, hasta tiradores de puerta. El primero de estos concursos dio origen a la obra más representativa de

7 Por ejemplo, en Estados Unidos la General Services Administration (GSA) creó en 1963 el Programa de Arte en la Arquitectura y en 1967 se elaboró el Programa de Arte en Espacios Públicos dependiente de la Agencia Nacional para las Artes. Estas instituciones expresan la preocupación de la época por el diseño, el arte urbano y la integración al medio ambiente urbano.

8 El arte en el espacio público ha tenido diversas transformaciones durante el siglo XX, las que Rosalind Krauss (2008) conceptualizó como arte en el campo expandido. La situación comenzó a complejizarse y los límites trazados por el pensamiento moderno tradicional parecían diluirse frente a los hechos, “... pensar el complejo es admitir en el dominio del arte dos términos que anteriormente habían estado prohibidos en él: paisaje y arquitectura, términos que podrían servir para definir lo escultural (como empezaron a hacerlo en el modernismo) sólo en su condición negativa o neutra." (Krauss 68)

9 La CORMU era la Corporación de Mejoramiento Urbano creada en el año 1965 donde participaban principalmente arquitectos. El objetivo de la CORMU era regular el desarrollo urbano de las ciudades que comenzaban a crecer de forma desmedida en aquella época, producto de las múltiples migraciones del campo a la ciudad y en pleno proceso de modernización del país. En este sentido, existía un interés en que los muros y distintas estructuras de la ciudad fueran un aporte a la cara de Santiago a través de elementos decorativos en las obras urbanas. 
este grupo: el Paso Bajo Nivel Santa Lucía ${ }^{10}$. De un total de 19 proyectos presentados al concurso, el elegido fue uno de los diseñados por el DI, el de Iván Vial, pero los tres artistas participaron activamente en la ejecución y se considera una obra del grupo.

$\mathrm{El}$ análisis de esta obra permite observar dos elementos relevantes respecto al concepto de diseño integrado y que constituyen las dos caras de una misma moneda. Por una parte, el Paso Bajo Nivel Santa Lucía resulta un ejemplo clarificador de la conceptualización amplia de la idea de arte integrado en el nivel del proceso de trabajo. Por otra parte, es una obra paradigmática de arte urbano planificada según la función de la estructura urbana en la que se genera y, por tanto, involucrando al sujeto espectador.

Integrado al proceso de trabajo hace referencia a la incorporación del artista en el equipo que planifica la obra urbana, siendo este un profesional más que realiza su labor. Por ello Martínez Bonati expresaba "(la del artista) es la labor de un especialista como los otros, que concurre a la definición formal de este trabajo colectivo" (La Quinta Rueda 4) Creemos que para el grupo significó un positivo impacto la tendencia generalizada de expansión de los límites del arte (desde el happening hasta el land art) y principalmente la fluencia del emergente movimiento minimal, al que se vieron expuestos durante sus estudios en el Pratt Institute. El minimal problematizó la praxis del arte y la concibió como un trabajo e hizo de los materiales industriales su materialidad predilecta ${ }^{11}$. A los planteamientos del minimal, se une la discusión, en estos mismos años en el ámbito de la arquitectura en Chile, respecto a las posibilidades de los materiales industriales, que implicó una reflexión en torno a la integración de otras disciplinas, como por ejemplo el arte $^{12}$, en donde se acusa la necesidad de formar "talleres integratorios donde ingeniero, arquitecto, diseñador y artista, trabajaran juntos" (AUCA 23). Dicha discusión se puede vislumbrar específicamente respecto el hormigón armado, en la cual Eduardo Martínez Bonati ${ }^{13}$ estaba inmerso debido a su trabajo colaborativo con el arquitecto Miguel Lawner. Por tanto, la labor del artista como especialista en el entramado de relaciones de producción de una obra urbana se

10 El paso Bajo Nivel de Santa Lucía "sobrevive como un gesto de modernidad plástica en una urbe cada vez más carente de este tipo de hitos respecto al uso de nuevos materiales para la arquitectura capaces de servir en el arte público" (Navarrete 25). El estado de deterioro en el que se encuentra ha llamado la atención tanto de artistas y arquitectos, entre ellos destaca la arquitecta Pelagia Rodríguez, quién en los últimos años ha estudiado el mural con dedicación, para ofrecer evaluación de su estado de deterioro, así como una propuesta para su restauración.

11 Tal como lo haría posteriormente de forma explícita la obra del artista Richard Serra, Verbos (1968-1969) una obra que se interesaba por agrupar verbos en relación al trabajo del escultor, haciendo referencia a la naturaleza del proceso del trabajo físico en el espacio.

12 Miguel Lawner expone a propósito del uso del hormigón en Revista AUCA: "el artista debiera integrarse a la obra desde sus primeros comienzos no sólo por poner arte en un muro o un espacio, sino que en la planificación primaria de los espacios, colores, diseños y luminosidad", cuestión que Martínez Bonati en el mismo artículo comparte, diciendo que: "el problema es que por ahora solo ponemos la piel, la cubierta exterior ... en algunos encargos que recibí para trabajar el hormigón las formas básicas ya estaban consultadas y no habían posibilidades de crear formas o espacios nuevos, sólo la cobertura exterior estaba disponible" (AUCA 23).

13 Nos encontramos que "el concreto armado es para Eduardo Martínez Bonati (grabador y pintor) un material de impresión. El moldaje es la gran matriz impresora que deja su impronta en el concreto" (AUCA 23). 
observa más nítidamente al considerar el hecho de que el mural del Paso Bajo Nivel, fue presentado en asociación con la empresa IRMIR, la que posteriormente elaboró en conjunto con los artistas los vitrocerámicos de dos por cuatro centímetros para la obra. Es decir que su trabajo, no es un aditivo posterior, sino que es un trabajo considerado en la proyección de la obra, en este caso una obra urbana.

A diferencia de muchas obras, principalmente esculturas, en el espacio público, el mural del Paso Bajo Nivel no consistió en trasladar una pieza de museo a la calle porque su diseño mismo fue concebido y realizado en el contexto de un proyecto mayor, constituyendo una parte de todo un conjunto de relaciones de trabajo. Constituye, así, una obra pionera y a la cabeza de las discusiones de la época en el arte occidental del momento. Como se menciona en el libro Chile Arte Actual "hay otras obras en que el artista se integró a un grupo de planificadores urbanos e ingenieros, como fue el paso inferior Santa Lucia, ejecutado en $1968^{14}$, por los artistas Eduardo Martínez Bonati, Iván Vial y Carlos Ortúzar." (Ivelic y Galaz 356). Evidentemente, el arte integrado al Paso Bajo Nivel significó una nueva forma de comprender el proceso de trabajo y comunicativo, así como las dinámicas colectivas en que convergían las diversas especialidades, pero no era posible realizarlo de otra manera. Destacando esta idea de la dificultad del medio el arquitecto de la CORMU, Víctor Morand indicó que una de las dificultades de esta obra fue el carácter colaborativo: "la verdad es que ni los artistas ni nosotros estábamos preparados para enfrentar una iniciativa como ésta. El arte urbano rebasa los límites del trabajo individual" (Ercilla 1971).

A partir de lo anterior se desprende la otra cara del concepto diseño integrado al que hacía referencia la práctica del DI. En efecto, dicho trabajo no consistió en llevar un boceto de un dibujo al espacio público, sino proyectar un diseño para esa obra específica. El paso bajo nivel destaca por su composición geométrica de líneas sinuosas en tonos azules, celestes y blancos, que suben y bajan produciendo una sensación de movimiento. Su diseño fue elaborado considerando el tránsito de los automovilistas, de modo que las líneas guían el camino en su movimiento sin que entorpezcan la concentración ni el tránsito. Sobre esto se expresa Vial: "Mi proyecto tiene formas alargadas que induzcan al conductor a tomar una dirección, a salir del túnel. En resumen, podría decir que el mural está compuesto por formas direccionales de fácil lectura." (PAULA 85). Algo similar exponen Ivelic y Galaz sobre este proyecto: "La composición y distribución, como igualmente la aparición y desaparición de las zonas azules, grises o blancas, o el trabajo de forma y contraforma, solo es posible experimentarlo cuando se viaja en automóvil a lo largo de su trayecto." (356). Aun así, la obra generó polémica: "esta simplicidad-para algunos aparentemente aburrida- del

14 Hemos encontrado en las diversas fuentes diferencias significativas respecto a la ejecución del mural, nos quedaremos con la que lo señala en 1970, ya que es la que nos han dado los artistas. 


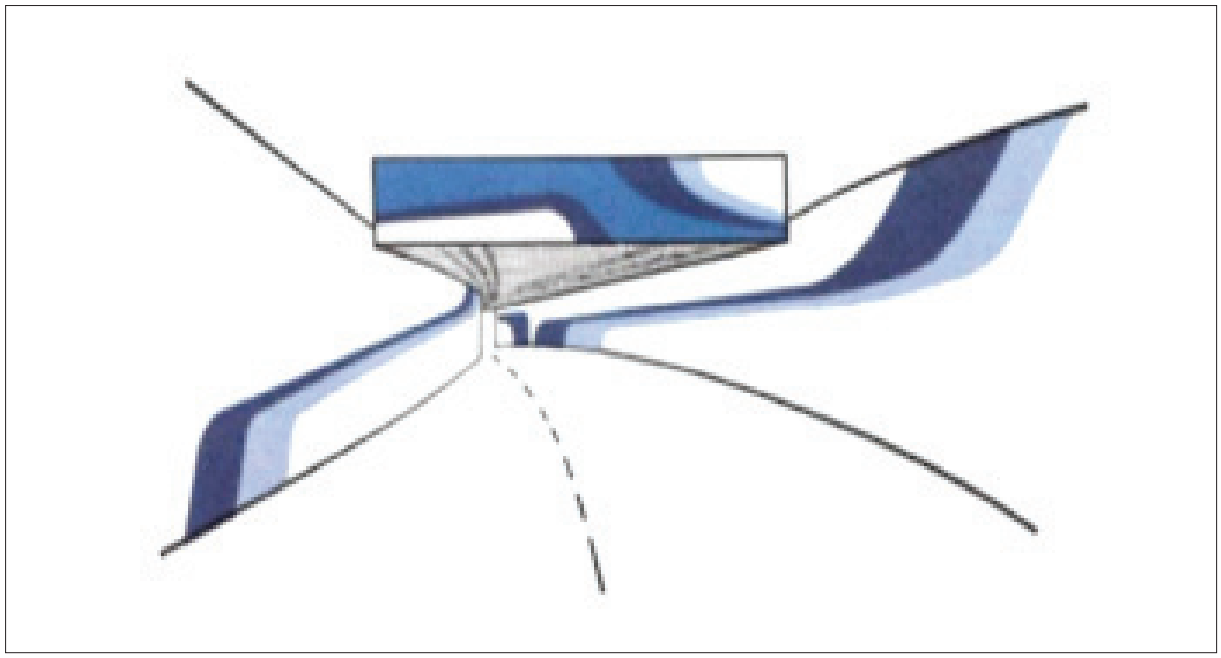

Figura 1. Boceto Paso Bajo Nivel ${ }^{15}$

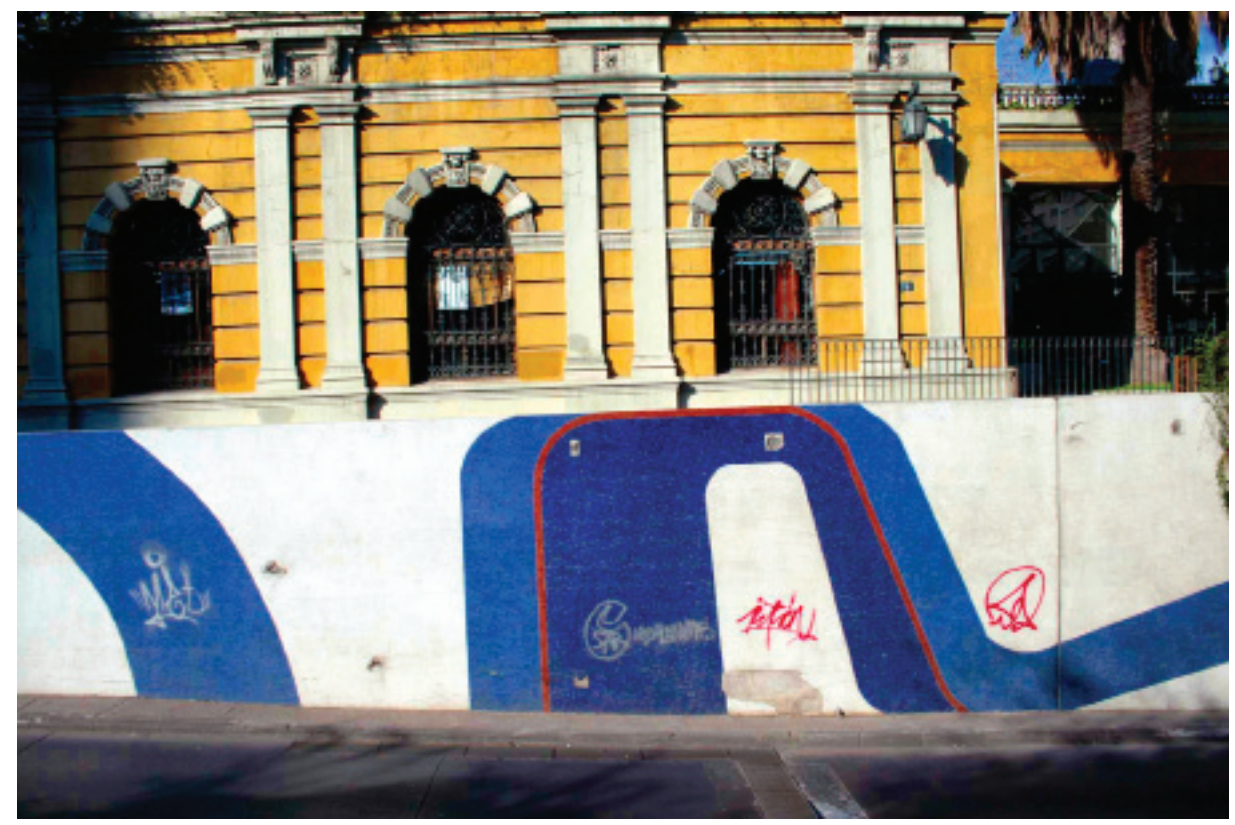

Figura 2. Fotografía actual Paso Bajo Nivel ${ }^{16}$

15 Imagen de boceto realizado por Iván Vial, Paso Bajo Nivel Santa Lucía. Fuente: Revista AUCA, archivos Eduardo Martínez Bonati.

16 Fotografía Paso Bajo Nivel 2009. Fuente: Stella Salinero Rates. 
proyecto de Iván Vial determinó su triunfo sobre otros quizás más bonitos" (PAULA 85). Lo anterior nos sugiere lo que parecía ser a nivel general en Chile una tendencia a favor de las obras figurativas en detrimento de la abstracción geométrica y el arte cinético, sin comprender que en el caso de esta obra urbana vial, las ideas de movimiento en conjunto con el espectador/automovilista y la inexistencia de importantes puntos de atención sensorial eran la base para un buen diseño de arte integrado.

Posteriormente y con la incorporación de Angélica Quintana, el DI participó y ganó el concurso para la remodelación del complejo de edificios San Borja (1973), para la cual proyectaron la base de una plaza o patio duro en función del diseño de baldosas según la geometría básica, utilizando el cuadrado y sus múltiples líneas derivadas de sus diagonales, verticales y horizontales. La propuesta contaba también con mesas para jugar ajedrez o bien para ser utilizadas de diversas formas por los habitantes. Incorporando formas simples y espacios de encuentro, el proyecto consideraba la habitabilidad y uso del lugar y no meramente el diseño estético. Sin embargo, este proyecto nunca se llevó a cabo, lo mismo sucedió con la propuesta para el mural del Aeropuerto de Cerro Moreno de Antofagasta (1973) que también resultó ganadora, pero dada la situación producida por el golpe de Estado de 1973 no se construyó. Este hecho histórico desencadenó la disolución del DI.

\section{La democratización del arte y el diseño: lo bello como necesidad del ser humano}

Nos detendremos en la concepción del diseño del DI, si bien ya hemos visto que no se puede interpretar fuera de la idea de que es un "diseño integrado", para conocer un poco más su práctica concreta que rebasaba cualquier clasificación. En este sentido las palabras de Angélica Quintana son iluminadoras: "Ellos hablaban de que era todo arte y que en cierta medida el diseño, el concepto de diseño hace la vida más agradable y más fácil, y el diseño se refiere a las piezas que son industrializadas." (Entrevista personal 2012). El DI identificó que el consumo de imágenes u objetos para goce privado existía como mercado en el país, es decir, que era un nicho posible de cubrir para ellos. Iván Vial expuso que "anualmente se importan diez mil oleografías, lo que está demostrando que existe un mercado para... obras de arte" (PAULA 87). La idea de una masificación parecía entonces factible. Por supuesto que esta obra no tendría las características de la obra de arte tradicional en cuanto no sería única e irrepetible, ni tampoco sería realizada con materiales caros (óleo, mármol, etc.) sino que se adaptaría a otros materiales de bajo coste como el plástico, la cerámica, el metal o la madera aglomerada. Siguiendo esta idea, Martínez Bonati expone su pensamiento como grupo: "creemos que el arte debe ser para todos. El buen gusto no tiene por qué ser patrimonio de unos pocos, porque después de todo, lo bello es una necesidad del ser humano" (PAULA 87). Esta necesidad humana que expresa el artista como una máxima 
del DI, la podemos ver en la voluntad de ir embelleciendo nuestro entorno, desde la escala macro constituida por las obras e intervenciones urbanas en el espacio público, hasta lo micro, que serían pequeños objetos, imágenes y esculturas que convivirían en nuestro espacio cotidiano ${ }^{17}$. Si bien dichos artistas aspiraban a una producción industrial para hacer posible un acceso masivo a estos bienes, en el entendido que "un buen cuadro o una escultura no tendría por qué ser más cara que una buena olla o una buena toalla" (PAULA 87) esta producción nunca tuvo lugar, en parte porque las condiciones materiales de producción de que disponían no lo posibilitaban ${ }^{18}$, en parte también, porque el colectivo tuvo un abrupto final dado por las condiciones políticas del país. Por tanto, no hemos podido conocer cómo hubiesen sido esas obras en serie y cómo se hubiese percibido un arte "industrial" en el Santiago de esa época ${ }^{19}$. Sin embargo, queremos destacar que el Taller del DI en su modo de producción más cercano a lo artesanal, combinó sus nuevos conocimientos de materiales y tecnología, a su interés por el espacio público y el acceso democrático a lo bello.

En este sentido la palabra diseño en el nombre del grupo no se refiere a una disciplina o campo de conocimiento específico, sino a la idea proyectada siempre presente antes de su realización material (diseño integrado) y, como tal, a una acción propia de toda labor. Su noción de diseño implicaba una concepción amplia, cercana a la que declara que “... el diseño, despojado hasta su esencia, puede definirse como la capacidad humana para dar forma y sin precedentes en la naturaleza a nuestro entorno, para servir a nuestras necesidades y dar sentido a nuestras vidas" (Heskett 7). En efecto, constituir un Taller de Diseño abría el camino para incluir otros verbos al quehacer del grupo tales como integrar, dibujar, imaginar, jugar, experimentar, construir, reconstruir, usar, discutir y proyectar una idea, que luego podía ser llevada a cabo con la asistencia de otros procesos productivos. Es decir, aludía a un proceso más amplio que el que constituye la idea tradicional del arte, concebido como la "creación" artística de la genialidad individual. Particularmente en el DI esto se vislumbra al decidir trabajar como un colectivo y luego al concebir que los y las artistas tienen una labor en la sociedad, este ayudaría al progreso y mejoramiento de la vida tal, y

17 Esta preocupación y democratización de lo bello integrado en la vida cotidiana también lo que expresó el arquitecto Hugo Gaggero quién cuando lo entrevistamos nos relataba su experiencia en la incorporación de arte en el edificio de la UNCTAD III, la que fue gestionada y organizada por Martínez Bonati: “(Hacer) una plaza y que los juegos de los niños no sean feos porque da lo mismo van a jugar igual ¿te fijas? Hay que viajar a los países nórdicos para aprender. Hay un ministerio de diseño, nada es feo, nadie fabrica un objeto feo porque no tiene paso del gobierno, eso hay que hacerlo... Hasta cuándo consumen objetos feos." (Entrevista personal a Hugo Gaggero 2012)

18 Al respecto en el artículo titulado "Un arte para la ciudad" se expone lo siguiente del DI: "Han sabido utilizar sus conocimientos para un medio más modesto, pero que no se queda atrás en cuanto a un arte de integración social" (Revista Viaje, 1971, № 449)

19 En esta línea, quizás quién si llegó a ese objetivo fue Carlos Ortúzar, cuando trabajó diseñando y produciendo diversos objetos, pero sobre todo lámparas para la tienda TERRA de Tessa Aguadé. Aguadé expone: "Él (Carlos Ortúzar) diseñó más de veinte modelos de lámparas, y yo las vendía acá (drugstore) ... facturaba la lámpara volantín, esa que es famosa, que el arquitecto Federico Sánchez dice que es el mejor diseño que ha habido en Chile hasta hoy. La lámpara es súper linda, pero compleja, es una lámpara con tela, además con madera y una parte que hay que mandar a hacer a una tornería de fierro" (Entrevista personal a Tessa Aguadé 2012) 
como ha expresado Martínez Bonati: "si se establece otro campo de relación entre el arte y la sociedad, las exigencias para los artistas serán otras” (Ercilla 1970). Y luego agrega "los artistas deberán aprender (...) comprometerse con cosas tan simples como una baldosa o el revestimiento para un muro" (Ercilla 1970).

Como ya sabemos estas ideas no eran nuevas, otros movimientos y vanguardias intentaron acortar las brechas entre el mundo del arte y la vida cotidiana. Sin duda se dejan sentir las influencias del Constructivismo y la Bauhaus que aportaron a los importantes debates del pensamiento y la praxis del arte en el mundo industrial y de la sociedad de masas durante el siglo XX, abordando "el problema de cómo la sociedad podía y debía cambiarse aprovechando la producción mecánica para extender el poder del arte a todos los estratos sociales" (Heskett 28). La práctica e ideas del DI expresaban su cercanía al ideal del artista-diseñador, el cual sigue siendo un elemento significativo en el diseño contemporáneo (Heskett). Y no es de extrañar que el pensamiento del DI girara en torno al deseo y la utopía de la adquisición de objetos de arte por las masas en los supermercados y tiendas. Considerando estos elementos, resulta más fácil comprender por qué el DI no se cerró a un género específico del arte ni a una disciplina en particular. Sus procesos de producción implicaban desde la discusión de las ideas en grupo, pasando por el diseño y análisis desde sus diversos puntos de vista y el aporte de sus especializaciones, hasta llegar a la posible concreción material de las ideas.

Esta concepción del Diseño remite a lo planteado por Margolin cuando escribe: Personalmente prefiero una concepción mucho más abierta de la actividad del diseño, cuyo objetivo principal de investigación no se preocupe por justificar una esfera separada de pensamiento. Reconozco el valor de tal conocimiento, pero cuando este es buscado o definido de manera excesivamente estricta, los investigadores tienden a excluir otras perspectivas valiosas. (326)

Siguiendo esta idea, la apertura del concepto les permitía a los miembros del DI trabajar indistintamente el diseño de una baldosa, la construcción de una estructura cinética o la proyección de shows luminotécnicos, moviéndose cómodamente, bajo la premisa de los difusos límites del pensamiento y la práctica, del diseño, el arte, la construcción, el grabado, la ciencia, etc. Martínez Bonati, Ortúzar y Vial en el Taller “... han realizado trabajos que abarcan desde un mural hasta servilletas de mesa." (Ivelic y Galaz 108)

Es así cómo en el marco de las actividades de Museo '70 del Museo Nacional de Bellas Artes ${ }^{20}$ utilizaron un artefacto similar al "abstractoscopio cromático" del

20 Respecto a la vinculación de Carlos Ortúzar con la ciencia y sus estudios señala Tessa Aguadé: "En el año 70 Carlos fue al MIT. Es muy importante porque él trabajaba con toda la tecnología. En el fondo debiera haber sido un científico, un ingeniero, pero claro la parte del arte la tenía. Era muy creativo, pero siempre relacionado con la tecnología". Más adelante agrega "Cuando él llegó, quería iluminar con un láser la virgen del San Cristóbal y todos decíamos ¡qué loco! ¡qué loco! y habría sido genial, pero nadie sabía de un láser, nada, pero él ya quería iluminar la virgen del San Cristóbal con láser. Yo te estoy hablando del año 65, era muy adelantado y como tenía esa parte loca, bueno de repente le iban resultando las cosas, luchaba”. (Aguadé, Tessa. Entrevista personal 2012) 
científico e ingeniero Carlos Martinoya, para realizar unos shows luminotécnicos durante los espectáculos que allí se presentaron (danza, música y poesía). Este aparato $^{21}$ de la década de 1950 fue una fuente de inspiración para Ortúzar en sus shows luminotécnicos. Cabe destacar que el primer trabajo que realizaron como DI (1969) fue una escultura cinética que le encargó a Carlos Ortúzar la empresa Peugeot para instalar en sus dependencias, por lo que no es de extrañar que hayan querido seguir sobre esta misma línea y por ello podemos observar estos elementos tecnológicos ya integrados a su quehacer jugando con las percepciones del movimiento y la luz. Los shows luminotécnicos fueron ejercicios únicos, pero su lógica y medio técnico son reproducibles y, por tanto, se ajustan a las sociedades complejas de masas, apuntando hacia una democratización del disfrute de las percepciones sensoriales. Sobre el show luminotécnico expresa el artista: "esta máquina giraba y tiraba un plint de luz que pasaba por un proyector posteriormente, la luz se descomponía al chocar con los papeles de celofán y como las imágenes estaban puestas, una por un lado y otra por otro, se hacían unas formas increíbles" (Martínez Bonati. Entrevista personal 2012). Los objetos y las imágenes son construcciones que esconden un conocimiento técnico en su producción y distribución. Cada vez más, las diversas disciplinas y campos de conocimiento utilizan para su producción una mediación técnica. No es ninguna novedad hoy para nosotros, que los adelantos en ciencia y su aplicación técnica han revolucionado el mundo de forma acelerada. Sin embargo, la utilización de esta máquina durante las jornadas de Museo ' $70^{22}$ fue un hecho que adelantaba la visión de una sociedad altamente mediada por aparatos y, a la vez, la acción del DI expresaba la importancia de una concepción amplia de los procesos de trabajo y producción en el mundo de las artes y el diseño, que motivaba a explorar fuera de los límites impuestos por las disciplinas antes que reproducirlos mecánicamente.

21 El "abstractoscopio cromático" o también llamado "Robot que pinta", fue concebido, diseñado y construido por el científico Carlos Martinoya como una herramienta técnica en base a sus experimentos científicos sobre la naturaleza y percepción de la luz. Este aparato merece un análisis particular por las múltiples significaciones sociales y culturales que representa para su época -objeto en el que estamos trabajando actualmente- aquí aludimos a ella sólo en la medida que nos permite ilustrar la práctica del DI y la visión de su quehacer experimental en relación constante con la ciencia, la técnica y, en este caso específico, el espectáculo.

22 Es posible encontrar voces críticas que reconocieron el espacio vanguardista y de experimentación que abría esta instancia: "Los acontecimientos -Museo 70- son quizás lo más promisorio. Combinan la luz el sonido y el movimiento en espectáculos siempre cambiantes (...) El que se efectuó en enero de este año agrupó a grupos de jóvenes (más de 500) que en ocasiones no entrarían a los así llamados "sagrados recintos de arte". (Jorge Vasari, El Mercurio, 1970). Hemos encontrado otra mención en la prensa de la época de los shows luminotécnicos: "Para la entrega de premios para cantantes y artistas de televisión, mezclaron la fotografía y los efectos ópticos en un espectáculo público que tuvo gran acogida en los asistentes al teatro donde se realizó la ceremonia” (Viaje 26) 


\section{El sentido del taller como espacio creativo en la práctica del DI}

Así como los integrantes del DI redefinieron su lugar en el espacio social asumiendo una labor en la práctica del "diseño integrado", creemos que una de las características dentro del taller del DI fue la convivencia de la individualidad del artista y del trabajo colectivo, ya que ellos decidieron compartir su taller, lo que no puede verse como una situación azarosa. Consideramos este punto primordial para el éxito de sus obras, dado por la primacía del sentido creativo del grupo cristalizado en la figura del taller, en el espacio común de trabajo donde emergen, se discuten, se proyectan y se realizan las obras. La dinámica no se distancia de los modos tradicionales del funcionamiento de un taller de artista. Sin embargo, de acuerdo a lo que nos explica Martínez Bonati ésta se modificaba según el tipo de obra, es decir, se adaptaba a las diversas necesidades que surgían de los proyectos individuales utilizando y explorando diferentes modos de trabajo. Por ejemplo, el artista recuerda cómo surgió la idea para la obra para la exposición Las 40 medidas (1971) en el Museo de Arte Contemporáneo, como apoyo al triunfo de Salvador Allende:

Para hacer esas cosas se operaba así: se sentaba el Carlos por ahí y el Iván por acá y a mí me tocaba pasear, pasear e ir soltando ideas... entonces, el modo de actuar de ellos era cómico, porque se reían a carcajadas ¡Qué pésimo! ¡Qué horrible! Y yo tenía que dar vuelta y vuelta e ir soltando ideas y de repente empezaban a salir ideas más o menos mejores, hasta que salió la del cubo. En el momento que la solté, sabía que era la ideal. Los quedé mirando y se quedaron callados. Ah bueno yo puse la idea, ustedes ponen las manos (Entrevista personal 2012)

El carácter lúdico de la obra el Cubo requería otra forma de operar: lo que hoy se conoce popularmente como Brainstormig, o "lluvia de ideas". Ésta se dirige a potenciar la capacidad creativa grupal, postulando que las ideas se vuelven más efectivas trabajando en grupo que por separado, en un ambiente relajado e informal, como el que nos presenta el artista en su relato. Mientras más ideas se volcaban sobre Las 40 medidas, más cerca se llegaba a la solución de la forma. Finalmente, decidieron construir un cubo de 2.30 metros de alto por 2.30 metros de ancho y por 2.30 metros de largo, con diversos personajes en cada una de sus cuatro caras internas: un cura, un león, un nudista, un ángel, señoras y señores desnudos, e incluso en la parte inferior hicieron un agujero para un perro. Estos personajes tenían los rostros recortados de modo que quién estuviese afuera y quisiera mirar, estuviera obligado a pasar a formar parte del cubo, prestando su propio rostro a alguno de los personajes. La obra jugaba con varios elementos para crear una ilusión, es decir, explotaron las cualidades ópticas del objeto construido para generar una experiencia perceptiva. Compuesto de una forma muy simple, el cubo mezclaba una puesta en escena de diversos personajes en tamaño natural, en un contexto que se separaba totalmente del exterior. Al estar cerrado y tener dimensiones de escala humana, quitaba toda referencia perceptiva del entorno e incorporaba a los 
espectadores como actores en la obra. Por otra parte, la forma de cubo implicaba que cada persona no veía su personaje, sino solo los de los demás, motivando el cambio de lugar para ver el primer personaje, por el cual se había sido parte de esa escena. De esta forma, el cubo era un juego de reconocimiento e interacción en distintos papeles sociales, a través de la creación de un contexto fuera de contexto, en donde contenido $\mathrm{y}$ forma (sorprender a la gente y hacerlos participar) expresan una univocidad ${ }^{23}$.

El taller permitió el trabajo colectivo y la comunicación entre los artistas, en el sentido que debieron aprender a comprender lo que los otros querían expresar y crear para que las soluciones e ideas se generaran satisfactoriamente. En el Taller la palabra hablada, desde la conversación informal hasta el traspaso de información cara a cara, es el medio principal a través del cual se coordinan las acciones, porque además “... podemos consultar a alguien de inmediato, discutirlo de cabo a rabo una y otra vez, mientras que cuando leemos una página escrita podemos discutir con nosotros mismos sobre lo que hemos leído, pero no tenemos la retroalimentación del Otro" (Sennett 221).

El sociólogo Richard Sennett nos brinda una definición abierta y general de taller, a partir por ejemplo, de los rasgos en común que puede haber entre un taller medieval y un laboratorio científico de hoy. El taller del DI era uno de estos pequeños talleres de relaciones cara a cara que describe Sennett. Ubicado en la casa de Carlos Ortúzar y Tessa Aguadé, tenía al mismo tiempo un espacio común y talleres individuales. Allí los integrantes se planteaban al mismo nivel, no solamente al estar cara a cara, sino porque la jerarquía o autoridad no estaba representada por un maestro u otra figura preponderante. Más bien sugerimos, que la autoridad se podría expresar como un bien común del taller, representado por el sentido de pares calificados para la empresa que allí se desarrollaba. No se trata de un taller medieval como los que describe y estudia Sennet, de modo que no hay maestros y aprendices, sino campos de conocimiento y prácticas que resultaban un aporte a los otros, de manera que todos eran aprendices y maestros en la medida en que mostraban su trabajo y estaban bajo el escrutinio de los otros por libre decisión. El DI constituyó un taller moderno, en el sentido que la modernidad implica un cuestionamiento a la autoridad tradicional, el surgimiento del sujeto y con él las ideas de su libertad e igualdad constitutiva ${ }^{24}$. Baste recordar que todos los integrantes trabajaban como catedráticos en facultad de artes de la Universidad de Chile y que a su vez, habían compartido también la experiencia de especializarse en el Pratt Institute de New

23 Y justamente en correspondencia al carácter lúdico de su trabajo queremos resaltar lo que expone Martínez Bonati respecto a la experiencia de hacer la obra para la Peugeot: "nos entretuvimos como chinos porque realmente lo pasábamos muy bien trabajando juntos" (Entrevista personal a Eduardo Martínez Bonati 2012) Pensamos que esta cuestión también fue fundamental en su éxito como grupo.

24 Lo anterior en relación al sentido que le otorga Jürgen Habermas cuando expresa que "la modernidad se revela contra la función normalizadora de la tradición; en verdad, lo moderno se alimenta de la experiencia de su rebelión permanente contra toda normatividad." (2) 
York. Sin embargo, tampoco se trata de un trabajo autónomo sin interferencia alguna (Sennett 2009). La autonomía, aún cuando es la característica distintiva de la separación de las diversas esferas, y por tanto la idea que está en la base de la noción moderna de artista o creador, ha sido cuestionada duramente desde el siglo XX y en la práctica del DI dicha crítica está presente. Junto con lo anterior, cabe destacar que el DI principalmente trabajaba a partir de convocatorias: a exposiciones como la de Las 40 medidas o a postulación a concursos ${ }^{25}$. Como ya hemos visto, al tratarse de arte integrado al medio ambiente urbano, primaban otros aspectos, como el de la técnica y los materiales, lo cual hacía que el modo de operar sobe el trabajo fuese distinto. Al respecto Martínez Bonati explica:

“(En) otros trabajos, analizábamos el tema desde la técnica que se podía emplear. Después cada cual iba a su taller, proyectaba y nos reuníamos a ver lo proyectado. Entonces, ahí venían las discusiones ¿entiendes tú? que esto está bien, esto mal, que no le metas tanto colorido aquí. Así se discutía y después se volvía cada cual a su taller a seguir trabajando." (Entrevista personal 2012)

Esta reflexión interna del DI respecto a cada proyecto, se retroalimentaba con el pensamiento en permanente construcción producto de sus respectivas cátedras en la Universidad de Chile (Grabado, Martínez Bonati; Materiales, Carlos Ortúzar; Dibujo, Iván Vial). De acuerdo a lo narrado por el artista, cuando cada uno trabajaba en un mismo proyecto, sus dibujos aunaban lo que habían discutido durante todo el proceso creativo así como, su particular punto de vista en torno a la obra y al lugar específico al que estaría dirigida, intentando solucionar los problemas que este planteaba. $\mathrm{Si}$ seguimos a Sennet al decir que "volver una y otra vez a una acción permite la autocrítica" (Sennett 53), en el entendido de que la repetición y el trabajo manual es una parte fundamental de la práctica dentro del taller, cada uno de los ejercicios o fases por los que pasaba una propuesta antes de estar terminaba, hacía surgir la crítica y a su vez, la autocrítica, enriqueciendo el trabajo final. En el caso del paso bajo nivel Iván Vial expresó lo siguiente: "Yo me ceñí a la tesis que nos habíamos formulado en el Taller. Aunque cada uno presentara un proyecto, asesorado por los otros, la tesis era la misma y por eso, cualquiera que triunfara, era un triunfo para el equipo. Nosotros estudiamos el pasonivel y decidimos que había que darle importancia a la "lectura" del mural a una velocidad automovilística" (PAULA 85)

¿Hacia dónde se dirigía el DI? En consideración a lo expresado por el grupo a diferentes medios de comunicación de la época, podemos sugerir que el DI se encontraba a medio camino entre el taller artesanal de producción de objetos únicos

25 Las propuestas que se salen de estos formatos concretos no fueron particularmente desarrolladas por el DI, lo que no significa que no tuvieran ideas de intervenciones propias. Por ejemplo, El show luminotécnico realizado en el marco de las actividades multidisciplinares de Museo 70 en el MNBA en 1970 fue una de ellas; otra, serían las baldosas modulares que plantearon como suelo distintivo por comuna, las que desgraciadamente nunca se hicieron. (Entrevista personal a Eduardo Martínez Bonati 2012). 
y el taller industrial o la factory (al modo de Andy Wharhol que producía obras de arte de forma industrial) Al respecto el DI expresó que el arte debería adecuarse a la sociedad moderna y uno de esos modos sería adoptar una producción industrial.

\section{A modo de conclusión}

Las propuestas del DI, como se ha visto, emergen a partir de los conceptos que conforman su nombre y constituyen ideas propias del desarrollo del pensamiento asociado a los ámbitos estéticos durante el siglo XX. En tal contexto estos conceptos se encuentran en relación a las ideas modernas sobre las autonomías de las esferas y sus prácticas, así como la crítica a éstas desde las distintas disciplinas. Es así como el Taller denota un espacio físico de trabajo grupal que permite un diálogo a través de la palabra hablada y las experiencias derivadas de las relaciones horizontales, legitimadas por las especializaciones de cada uno de los miembros del DI. Este espacio era el más idóneo para una práctica que se dirigía a sobrepasar la idea de la autonomía del arte, haciendo propio el concepto de Diseño desde una perspectiva amplia, para la realización de trabajos que visitaban permanentemente otras disciplinas. Por lo que resulta evidente que el concepto de Diseño Integrado connotaba su propia naturaleza multidisciplinar dirigida a la realización de proyectos que se integraban o incorporaban -durante su proceso creativo- a otros ámbitos y/o proyectos de otras disciplinas como la arquitectura y el diseño urbano. Estos elementos fortalecían las ideas sobre salir al espacio público y concebir objetos industriales, ambas en el contexto de la sociedad de masas y que en gran medida estuvieron influenciadas por su paso por el Pratt Institute y el MIT, donde convergieron en el aprendizaje de nuevas ideas, tecnologías y materiales. En este sentido, podemos decir que el DI contribuyó a la cara "moderna" de la ciudad de Santiago a través de sus obras, lo que sin duda expresa un momento caracterizado por desplazamientos en las esferas de la producción, la técnica, ideologías políticas y movimientos en el mundo del pensamiento y las artes provenientes de las diversas escuelas mencionadas, que confluyeron para dar origen a una situación particular de relaciones y un contexto social y político que daba sentido a su quehacer comprometido con el arte integrado en el medio ambiente urbano ${ }^{26}$. Los elementos analizados, que se manifiestan en las obras que realizó el DI, indican la importancia de su estudio como colectivo y su rescate, especialmente a la luz de diversas transformaciones ${ }^{27}$ que está viviendo el arte y diseño urbano en la ciudad Santiago.

26 Corresponde al concepto de Momentum del filósofo Jacques Rancière (2010).

27 Nos referimos a la extensión y cambio estético/material del metro de Santiago, la gentrificación de la ciudad, la destrucción del mural de Thierry Noir en el barrio Lastarria, la creación de nuevos parques y autopistas, la implementación del Transantiago y la reciente remodelación de edificio UNCTAD III, actual GAM tras el incendio que lo aquejara, entre otros eventos. 
Al mismo tiempo, observamos diversas líneas que se abren para investigaciones futuras sobre este grupo, por ejemplo, problematizar su práctica en comparación con otros espacios de diseño colaborativo en Chile, como lo fue SERCOTEC durante la misma época, para ver las posibles relaciones entre distintas disciplinas en el contexto de la Unidad Popular. Otro punto necesario de ahondar es la vinculación del DI con la ciencia y la tecnología, y desde allí vislumbrar el impacto del paso de los integrantes del DI en EEUU en los diversos centros a los que acudieron (Pratt Institute, MIT), en donde el caso de Carlos Ortúzar se presenta como paradigmático en la escena artística chilena. Conocer en profundidad el debate en torno al medio ambiente urbano que se estaba llevando a cabo en Chile durante ese período y vincularlo a la práctica de estos artistas ya sea mediante los concursos CORMU y encargos personales. Y por supuesto profundizar en el conocimiento de sus obras, en análisis exclusivos que las vinculen a los lugares en los que estuvieron y/o fueron proyectadas. En este punto es necesario continuar una labor de archivo, pues muchas de las obras ya no existen e incluso no se han encontrado sus registros, y porque en general hemos podido constatar a través de diferentes artículos en la prensa nacional el entusiasmo con el que se miraba al DI, sus proyectos e ideas. Dichas profundizaciones y su respectiva labor de archivo permitirá reconstruir una parte de la historia del arte Chileno de la década de 1960 y principios de la de 1970 de la que aún falta mucho por (re) conocer.

\section{Referencias}

Aguadé, Tessa. Entrevista personal. 31 de mayo 2012.

Gaggero, Hugo. Entrevista personal. 18 de junio 2012.

Gómez Aguilera, Fernando. "Arte, ciudadanía y Espacio Público". On the W@terfront. $\mathrm{N}^{\circ}$ 5. Fecha ingreso Marzo 2004. <http://www.ub.es/escult/Water/N05/W05_3. pdf $>$. Sitio web.

Heskett, John. El diseño en la vida cotidiana. Barcelona: Gustavo Gili, 2005. Medio Impreso.

Ivelic, Iván y Galaz, Gaspar. Chile arte actual. Valparaíso, Chile: Editorial Universitaria Universidad Católica de Valparaíso, 1988. Medio Impreso.

Krauss. Rosalind. "La escultura en el campo expandido" La posmodernidad. Hal Foster (Ed.). Barcelona: Kairós, 2008. 59-74. Medio Impreso.

Lawner, Miguel. Entrevista personal. 27 de junio 2012.

Margolin, Víctor. Las Políticas de lo artificial. México: Designio, 2005. Medio Impreso.

Martínez Bonati, Eduardo. "Un arte de anti museo". La quinta rueda 15 (1972). 4.

Medio Impreso.

---. Entrevista personal. 3 de abril y 9 de Julio 2012.

---. “Un arte para la Ciudad” Revista Viaje 449 (1971). Medio Impreso. 
Navarrete, Carlos. Carlos Ortúzar. Presencia y Geometría. Santiago: Metales Pesados, 2010. Medio Impreso.

Pérez, Francisca. Arte Minimal. Objeto y sentido. Madrid: Machado Libros, 2003. Medio Impreso.

Quintana, Angélica. Entrevista personal. 10 de mayo 2012.

Rancière, Jacques. Momentos Políticos. Buenos Aires: Capital intelectual, 2010. Medio Impreso.

Saúl, Ernesto. "Compromiso con una baldosa”. Revista Ercilla (1971). Medio Impreso. Seloski, Silvia. "Hormigón Visto". Revista AUCA 19 (1970). 19-24. Medio Impreso. Sennett, Richard. El Artesano. Barcelona: Anagrama, 2009. Medio Impreso.

Sierra, Marilú. "El arte debe ser para todos". Revista PAULA 16 de octubre (1970). Medio Impreso.

Recibido: 25 mayo 2013 Aceptado: 11 diciembre 2014 